\title{
Research on the Key Issues in the Modern Volleyball Athletic Training
}

\author{
Yue $\mathrm{Li}^{1, \mathrm{a}}$, Tengteng Zhang ${ }^{1, \mathrm{~b}}$, Qiang Chen ${ }^{1, \mathrm{c}}$
}

Nanchang Institute of Science \& Technology, Nanchang City, Jiangxi Province, 330108, China

a

b

email:

cemail:

Keywords: Key Issues, Volleyball, Athletic Training, Physical training, Technical Training, Tactical Ability and Psychology, Moral Quality

\begin{abstract}
With the increase of the actual combat exercises, China's volleyball team has accumulated a lot of valuable experience in the long-term combat. At present, there are still some problems to be solved in the development of volleyball athletic training. In volleyball training, the basic skill of the athletes is the key issue, and these basic techniques often determine the outcome of the game. Based on the author's teaching experience, this paper analyzed the key issues of modern volleyball athletic training from the physical training, technical training, tactical ability and psychological, moral quality, hoping to popularize and improve the volleyball sport in colleges and universities, and provide reference basis for the healthy development of the college volleyball team.
\end{abstract}

\section{Physical Training}

The physical training of the players is mainly to improve the physical function of the body, and improve the function of the central nervous system and internal organs, so that it can adapt to the development of volleyball technical and tactical needs, to maintain a good competitive state, to extend the life of the sport, to prevent the occurrence of injury accidents. Physical ability is the foundation of mastering volleyball technique, and a good physical fitness is an important guarantee to improve the technical and tactical level of volleyball. Volleyball competition is intense, and the situation is complicated and changeable, which puts forward higher request to the athlete's body function, so it not only requires the athletes to have a good bounce, but also to have a quick response, good coordination and flexibility. Therefore, the athlete's physical ability level is increasingly becoming an important factor in determining the sports performance. To develop and improve the physical fitness of volleyball players, it is necessary to achieve the goal of scientific training through a program. With the extension of the training process of athletes, physical training should pay more attention on the combination of special requirements. Neglect of comprehensive physical training, a priority to highlight the special training or not reflect the special characteristics of the general physical training are contrary to the principles of scientific training.

Volleyball training can be divided into two major categories: basic exercises and supplementary exercises. Basic exercises include preparing for posture and movement technical and tactical exercises. Auxiliary means is a number of comprehensive physical fitness exercises, for example, in practice, the muscles of the major muscle groups and the muscles around each joint should be 
stretched. Let the athletes start the regular exercise from the neck, the shoulder, back, chest, hip, thigh, ankle joint, to elbow joint. Aerobic training can use jogging, football, basketball and other rhythmic activities. The arms and shoulder exercises can include swing arm and reverse direction ring from a kneeling position to push up position, and then from the push up into a kneeling position. Leg crunches, leg lift, both sides of the body bending activities can strengthen the strength of the trunk and abdomen. At the same time, more attention should be paid to the development of volleyball athletes physical training in an important part of the development.

\section{Technical Training}

Single technical training. First, paying close attention to the basic technical specification points to establish the correct dynamic stereotype. College students athletes has a strong acceptance, but the plasticity is also very big. If the coaches pay more attention to basic skills training and the standardization of action, the technical movements of the athletes will be able to form a correct dynamic stereotypes, and receive a multiplier effect. In the concrete teaching, for the new players, the basic training can be used for about two months. Using hand - to - hand movements to break down the exercise or practice a variety of simulations, so that the new players have a more correct action concept in the rational and perceptual knowledge. For example, the training of the block is generally arranged after the four basic techniques of pass, pad, buckle and serve. The student athletes interest in blocking is weaker than the previous, so they are not enough focus in the training, which is not conducive to the development of all-round special technology athletes. In the teaching, coaches should first explain to students, the block is the first line, and the offensive blocking technology has become a means of attack. Therefore, sufficient attention should be given to the block, in addition, the basic skills of volleyball in the pass and spiking standard teaching is difficult, so it should be payed a special attention. Second, paying more attention to the ball feeling to get a good sense. The ball feeling of volleyball players is a combination of the visual, auditory, tactile, and muscle of volleyball players. The coach's explanation to the volleyball sphere structure and the analysis of the position of the force and the touch in the technical movement can help young athletes to get the ball faster by practicing. Although the induction is very important, the most important part of the cultivation of the ball is touching ball frequently. In training, we should increase the number of touch ball of the players as far as possible, in order to enhance the feeling of the ball. With the increase of the special knowledge of volleyball and the accumulation of competition experience, after tens of thousands of times the ball training, the athletes will gradually form a clear and good sense of the ball.

Technical series training. Technical series training refers to the combination of two or more single technology to carry out the training, and this training can make technical training with tactical factors in line with the principle of actual combat. To carry out technical series training to do step by step, according to the technical level of the athletes and the technical association rules between the competition, the technology is reasonably combined to consolidate the technology, improve the ability to use technology and enhance the ability of tacit cooperation between players, laying the foundation for the formation and enrichment of the offensive and defensive tactics of the whole team. Special attention should be paid to the technical series teaching and training according to the actual situation of the team, so that the basic technology is not only accurate, and the technology in series to be more practical, to adapt to the needs of the game.

\section{Tactical and Tactical Awareness Training}

Tactical training. Tactical training is an important content of college volleyball team training, 
and a team's tactical level reflects the overall strength of the team to a large extent, and tactical training can be divided into tactical link training and tactical training system. Tactical link training is the basis of tactical training, and strengthening all aspects of training can make the whole tactical system training more perfect. The training is mainly based on the important degree of each system and the actual situation of the team. Tactical system training includes: receiving offensive tactical training organization system; spiking attack tactics training organization system; stopped the ball attack tactical training system, then offensive tactical training organization system, training the strong purpose, meet the actual needs, particularly helpful in cultivating the tactical awareness. The coaches in college volleyball team should pay attention to the following matters when organizing and training: (1) according to the actual situation of the team to choose appropriate tactics to carry out teaching and training; (2) teaching and training tactics should follow the principle from simple to complex, from easy to difficult to prevent the blind; (3) paying attention to the links between offense and defense, strengthening the technical and tactical training series to prevent the disconnection of each link.

Tactical awareness training. The tactics of volleyball consciousness is the team member in the movement of the accumulated experience, a comprehensive reflection of talent and knowledge, the players in the game, judgment, reaction ability, strain capacity, reasonable use of technology and tactics ability of generalization. Technology is the foundation of the tactics, and master technology must understand the tactical awareness of the use of technology so, only the effectiveness of technology. In addition through repeated international, inter provincial competition, athletes should also use some modern multimedia tools (such as video, audio, courseware, etc.) to enrich the knowledge, and visit the high level of professional team training and competition, and constantly growing experience, knowledge and ability. In the training, basic skills training and tactical training must be placed in an important position, and should run through tactical factors in technical training, the technical and tactical organically, in order to improve the ability of team members to use technology and tactical awareness training.

\section{Psychological Training of Volleyball Players}

The psychological training of volleyball players is a kind of to train, develop and perfect all kinds of psychological qualities and psychological qualities that must be possessed by the volleyball players when they are engaged in special sports activities. To carry out psychological training in a planned way, and to exert a good influence on the psychological process and personality of the students helps to promote and improve the mental ability of learning, training, and games under extreme stress conditions. Psychological training methods, mainly based on the psychological process of personality and psychological characteristics of students, from the perspective of the volleyball match in combat, the excitability of the central nervous system to regulate the use of the second signal system so as to achieve the optimum degree of scientific training.

\section{Ideological Education Work}

College athletes age, knowledge level determine their physiological psychological linkage reaction acumen, strong thirst for knowledge, thinking, attitude and plasticity, and grasping the ideological education of their work will have a positive impact on the development of athlete's life. Training style should be based on a positive guide, if the athletes have progress, we should give appropriate encouragement and praise, thus, ideological education and training are closely linked, so the coach must set an example by himself in order to strengthen the ideological education of athletes to achieve the best training results. 


\section{Conclusion}

Similar to physical education and extracurricular sports activities, a good volleyball training is one of the basic ways to realize the goal of university education and the university sports task. Therefore, we should pay attention to the physical, technical, tactical and tactical awareness, psychological training to make them understand the purpose of training, to cultivate elite athletes.

\section{Reference}

[1] Pang Ming, Huang Dahua. On the physical training of volleyball training [J]. Journal of Jilin Institute of Physical Education, 2008,02:68+131.

[2] Zhao Shanwen. New features of high level volleyball training [J]. Journal of Nanjing Sport Institute (NATURAL SCIENCE EDITION), 2003,01:53-55.

[3] Zhao Saiqing. Analysis on physical characteristics and training of volleyball players [J]. Fujian sports science and technology, 2005,03:31-34.

[4] Zhu Zhengyu, Fu Qiang. The simulation training in volleyball training [J]. Journal of Harbin Institute Of Physical Education, 2004,02:84-85+87.

[5] Tian Jing. Study on the theory and practice method of physical fitness training for volleyball players [J]. Journal of Changchun University of Science and Technology, 2011,04:149-150. 